\title{
Using Essential Patent Index and Essential Technological Strength to evaluate industrial technological innovation competitiveness
}

\author{
DAR-Zen ChEn, ${ }^{\text {a }}$ WEN-YAU CATHY Lin, ${ }^{\text {b }}$ MU-HSUAN HuANG ${ }^{b}$ \\ ${ }^{a}$ Department of Mechanical Engineering, National Taiwan University, Taipei (Taiwan) \\ ${ }^{\mathrm{b}}$ Department of Library and Information Science, National Taiwan University, Taipei (Taiwan)
}

\begin{abstract}
The aim of this article is to develop new patent indicators for evaluating technological innovation competitiveness between companies. A novel indicator representing an industrial's patent performance, Essential Patent Index (EPI), was developed by incorporating information on who cited these patents and when these patents were cited, based on the assumption that both contribute to meaningful quality assessment. By combining EPI and Chi's well known Technological Strength (TS) indicator, a second novel indicator Essential Technological Strength (ETS) was developed to represent the innovation competitiveness of an individual company. In this study, patent performance of three high-tech industries in Taiwan were analyzed using ETS as well as the traditional TS for comparison. Results from this analysis demonstrated that ETS provided better insights by clearly verifying the latent influence of citations, reinforcing the impact of essential patents, and aggrandizing the differences of innovation competitiveness between companies.
\end{abstract}

\section{Introduction}

In the era of knowledge economy, innovation and $R \& D$ capacity of a company/institute will determine its competitive status in the international market. Increasingly, innovation and $\mathrm{R} \& \mathrm{D}$ capacity is surpassing land, labors and even the capital assets to become the major driving force for economic growth (WU, 2000).

Received August 8, 2006

Address for correspondence:

Mu-Hsuan HuAnG

Department of Library and Information Science, National Taiwan University, Taipei, Taiwan

E-mail: mhhuang@ntu.edu.tw

0138-9130/US $\$ 20.00$

Copyright @ 2007 Akadémiai Kiadó, Budapest

All rights reserved 
Therefore, the estimation of a company's performance is incomplete without the analysis of its innovation and $R \& D$ capacity indicators. Indicators such as innovation and R\&D budget, R\&D manpower, cooperation between industry and academic sector, as well as R\&D output have all been used for the assessment of innovation capacity. Besides these well-established indicators, company's achievement on intellectual properties such as patents owned has been shown to be a novel and direct measure for evaluation (CHEN et al., 2003).

According to the Global Competitiveness Report 2004-2005 (WORLD ECONOMIC ForuM, 2004) Taiwan's Growth Competitiveness Index (GCI) ranks fourth in the world. The most eye-catching performance by Taiwan is on the Technology Index item where Taiwan scores second behind only the United States. Among the indicators incorporated in GCI, the number of granted utility patents in the U.S. is probably the most direct and objective measure of a country's innovation capacity. It is just as a significant indicator for a company's innovation capacity, especially in the high-tech sector.

World Bank's Knowledge for Development (K4D) program created a Knowledge Assessment Methodology (KAM) to help the member countries understand the strengths and weaknesses in making the transition to the knowledge economy (WORLD BANK, 2005a). In KAM, Knowledge Economy Index (KEI) and Knowledge Index (KI) are used to aggregate the score of economic incentive and institutional regime, education and human resources, along with innovation and information infrastructure. On this scorecard, innovation system is one of the five indicators. It is composed of measures such as number of researchers in $R \& D$, number of patents granted by the USPTO and scientific and technical journal articles (WORLD BANK, 2005b). In 2005, Taiwan scored 20th in 128 countries world wide, and third among Asian countries.

Both Global Competitiveness Report and KAM apply number of patents to measure the technical innovation force of an economy. It is no doubt that the number of patents gives the initial picture of a country or a company's innovation capacity. Yet counting the patents along, as we will argue later in the article, is a rather imprecise measure as it fails to take into account of the value of each individual patent.

\section{Literature review}

\section{Patent citation analysis}

As early as the late 70 s, researchers in information science have started exploring the possibility of using the techniques of citation analysis on patents. In their pioneer work, ELLIS et al. (1978) argued that patent citation networks could identify key developments in the history of a specific technological domain. They also pointed out the potential of using patent citation networks for identifying possible investment 
venues. Then, authored by NUNN \& OPPENHEIM (1980), a network on prostaglandin was created by combining journal and patent citation. They argued that the citation network created by the combined approach presents a more realistic picture of the scientific development than either a patent or a journal citation network alone. Researchers also suggested the need for a subject-matter to have a well-developed patent history and the importance of subject knowledge in interpreting the network (DunlOP \& OPPEINHEIM, 1980; NUNN \& OPPENHEIM, 1980).

Patent citation analysis can be defined as "the study of patent citations for potentially determining a patent's value or, perhaps more reliably, the identification of potential licensing partners or leads based on the citation of an organization's patents by another company in the same or a completely different market space" (TRIPPE, 2003). It has been used as a measure of technological quality and influence, in studying diffusion of technological information, mapping the inter-related development of technical fields, and constructing technological indicators (KARKI, 1997). Several patent based indicators such as number of patents, patent growth rate, and Activity Index (AI), etc., have been used to quantitatively evaluate the innovative performance of industrials or countries (ALBERT et al., 1998; GARG \& PADHI, 1998; NARIN et al., 2000). With more value added patent information available, this kind of analysis is gradually incorporated into the current industrial competition strategies. Industrialists and national policy makers alike are paying more attention on several aspects such as how to control and predict the development of key technologies, the distribution of competitors, competitive and cooperative strategies, and hunting of important inventors. For example, it has been shown that citation-weighted patent stocks are more correlated with market value than patent stocks themselves. This fact is mainly due to the high valuation placed on companies that hold very highly cited patents (HALL et al., 2000).

\section{Indicators}

Stock-price effects of corporate R\&D expenditures have been used to provide useful but somewhat indirect evidence on the economic consequences of a company's inventive and innovative activities (HIRSCHEY \& RICHARDSON, 2004). Other than stockprice, several other measures such as new products, peer ranking of companies, research budgets have been used to assess a company's commitment to innovation (HIRSCHEY \& RICHARDSON, 2004; KOENIG, 1983; ROZHKOV \& IVANTCHEVA, 1998). In the academia, highly cited papers draw more attention, and citation frequency is widely accepted as a valid measure in science indicators and science policy analysis (ALBERT et al., 1991). Although citation behaviors and essentiality in scientific literature and patents are somewhat different, both treat citation counts as an interpretation of the impact of the information, whether it is an article or a patent (ALBERT et al., 1991; NARIN et al., 1987). 
As mentioned earlier, the application of patent citation analysis has gone beyond identifying the valuable patents. It has also been used for the purposes of estimating the value of institute, tracing knowledge flow and science diffusion, as well as the path of technology transfer (ACOSTA \& CORONADO, 2003; Hu \& JAFFE, 2003; MEYER, 2002). Simply counting the number of citation is no longer adequate for these diverse purposed. With the help from a more sophisticated patent registry system and the availability of machine-readable form, quality oriented indicators have been developed to meet the demands. Patent quality indicators analyze patent cites and cited data. For example, Patent Citation Number is an analysis of the influence of a specific organization's patent output on other organizations. Current Impact Index (CII) represents how often a particular company's patents are cited, compared with the average for the overall patent system; the more frequently a patent is cited, the more significant a technological impact it represents (BREITZMAN \& NARIN, 2001).

Some indicators use documents cited by patents and the time lag of the citations to characterize technological development at industry and national level. For example, Science Linkage can be used to reveal the relationship between the fundamental science and applied technology through the scientific papers and non-scientific papers and understand the character of the industry technology (NARIN \& OLIVASTRO, 1998). Technology Cycle Time uses the median of time lag of patent citation to measure the cycle time of patent technology exchange (NARIN et al., 2000).

With more developed indicators available nowadays, organizations started to measure innovative performance by using multiple indicators (HAGEDOORN \& CLOODT, 2003). The TR Patent Scorecard Report published annually by MIT Technology Review and CHI Research Inc. is one of the most authoritative reports. It ranks the United States patent portfolios of 150 top technology companies in eight sectors including aerospace, automotive, biotechnology/pharmaceuticals, chemicals, computers, electronics, semiconductors and telecommunications (TECHNOLOGY REVIEW \& CHI RESEARCH, 2004). Items such as Number of Patents, Current Impact Index, Science Linkage, Technology Cycle Time and Technological Strength are all included in this patent analysis report. Companies were then ranked according to their aggregated score of the "Technology Strength".

The TR Patent Scorecard Report is designed to represent the overall technology strength instead of the innovation force of a company, which is the main interest of this study. Our indicator includes not only technological strength but also innovation competitiveness representative of a company's R\&D capacity. Patent counts and their current impact, as well as other measures of technology strength are combined to create a single indicator representing a company's technology capability. Of particular interest is what we call the essential patents, which are patents that generate the most values and impacts. These essential patents are distinguished by their citing-patterns, citing assignees, technology factor and litigation factor. One important aspect of our research 
is the recognition that not all citations are created equal. Newest granted patents that are cited within a shorter period of time, citing newer references, and cited patents continually appearing in a longer period of time are assumed to have a higher quality. Patents which are cited by important assignee, spreading out of its home technical domain, and with different legal status should also earn more weight. These attributes are defined as the important essentiality of a patent as it is believed that they represent the most important criteria for a valuable patent.

Three Taiwanese industrial sectors: semiconductor, computer system, and computer peripheral and parts were chosen to test the validity of the indicator. These industries were chosen mainly because of their prominence in Taiwan's export-oriented economy.

\section{Methodology}

This research created different indicators from various perspectives. For technological competitiveness, the indicators from TR Patent Scorecard were adopted. For evaluating the innovation force, this research developed two new indexes, Essential Patent Index and Essential Technology Strength. The major thought of this research is based upon "each citation is unique and should not be treated under the same value". Besides, the influence of patents on innovation competitiveness is quite complicated. It may come from the side of citation or litigation factors. In the citation factor, the impact will be entangled with time, cited assignee, different citing patterns etc.

\section{Number of Patents}

Number of Patents is the most fundamental measure on which all other indicators are based. Analyzing number of granted patents over time reveals the development profile and trend in a specific industry. In our study, the number of granted patents of Taiwan industries in 2003 by the US Patent and Trademark Office (USPTO) was collected to create the industry development profile from the quantitative viewpoint. In this study, term $P_{i j}$ represents the number of granted patents by company $i$ in industry $j$.

\section{Current Impact Index, CII}

CII for a particular company is "calculated based upon the number of times patents issued this year cite the patents issued to the chosen company in each of the previous five years. The number of citations is then divided by the number of patents issued to the company in each of those five years, in order to produce an average citation rate. This rate is then divided by the average citation rate for all U.S. patents issued in each year during the same time period, in order to derive the Current Impact Index" 
(BREITZMAN \& NARIN, 2001). When the CII value is greater than 1.0, it means that granted patents owned by a certain company have been cited more frequently than average. Presumably it has better patent quality as its technology has a greater impact on the technology development of the industry. This study used the average cited number in 2003 of each patent and compared it to the average value from 1998 to 2002 for evaluating CII, the equation of $\mathrm{CII}_{i j}$ is given by:

$$
C I I_{i j}=\frac{C_{i j} / K_{i j}}{\sum_{i} C_{i j} / \sum_{i} K_{i j}}
$$

where $C_{i j}$ represents the cited number of patents in a certain year, and company $i$ produced in industry $j$ from previous five years, $K_{i j}$ is the number of patents, company $i$ produced in industry $j$ during the past five years.

\section{Technological Strength, TS}

While the Number of Patents provides a rough measure of a company's R\&D investment and output, the CII represents a company's technological impact manifested by number of citations (BREITZMAN \& NARIN, 2001). The product of the two constitutes a company's “Technological Strength" (TS). TS of $i$ company in $j$ industry, $T S_{i j}$, can be computed by its number of patents and its CII as follow,

$$
T S_{i j}=P_{i j} \times C I I_{i j}
$$

\section{Essential Patent Index, EPI}

The number of citations received is just a rough estimation of impact. At least two other factors need to be factored in to the evaluation of a company's technological impact, namely, the importance of the assignee and recency. Citations received from important assignees should represent higher impact. Another factor that needs to be taken into consideration is citation age. Older patent might accumulate more citation simply out of its seniority. Therefore, citations received from different assignees and with different seniority should not be treated as the same if the innovation competitiveness is to be captured with precision. Based on the above discussion, we have 
Axiom 1: The citation comes from an important assignee carries more influence.

$$
\Psi_{s}=\prod_{a=1}^{A_{s}} \psi_{a, s}^{n_{a, s}}
$$

where $\psi_{a, s}$ is the company-weighted factor of assignee $a$ which cite patent $s, A_{s}$ is the total number of companies which cite patent $s$, and $\mathrm{n}_{a, s}$ is the total cited times of patent $s$ by company $a$.

Axiom 2: The cited times of a patent will increase after it was granted for years. The citation appearing in early time has its importance and the influence and somehow age is in negative association with cited number.

$$
W_{z, q}=\frac{E_{z, q}{ }^{-1}}{\sum_{q=0}^{Q_{z}} E_{z, q}{ }^{-1}}
$$

where $\mathrm{E}_{z, q}$ is the total number of patents granted in year $z$ which are cited in year $z+q$. The essential integration $G_{s}$ is derived from the factor $W_{z, q}$ and $\Psi_{s}$, hence the equation is given by,

$$
G_{s}=\sum_{q=0}^{q_{\max }}\left(W_{z, q} \times e_{s, z, q}\right) \times \Psi_{s}
$$

where $e_{s, z, q}$ is the total cited times of patents $s$ (granted in year $z$ ) in year $z+q$.

Based on the essential integration $G_{s}$, this research defined the essential patents as those ranked in the top $25 \%$ of the patents. The $25 \%$ threshold comes from the idea of quartile calculation in general statistics. This research assumes that in a normal condition, the top $25 \%$ of the patents could constitute the elite class. Of course the cutting point upon which the elite class is defined can be adjusted for different purposes. For example a more selective measure can be created by including only the top $10 \%$ or even a smaller percentage.

EPN (Essential Patent Number) is therefore defined as the number of essential patents which receive high essential integration scores. Bases on the ratio of EPN to the number of total patents owned, a measure of a company's innovative quality, EPI (Essential Patent Index), can be established. The EPI of $i$ company in $j$ industry, $E P I_{i j}$ can be computed by its number of patents and number of essential patents as follow,

$$
E P I_{i j}=\frac{E P N_{i j} / P_{i j}}{0.25}
$$

where $E P N_{i j}$ represent the number of essential patents owned by $i$ company in $j$ industry. 
D.-Z. CHEN et al.: Essential Patent Index and Essential Technological Strength

\section{Essential Technological Strength, ETS}

In our study, ETS (Essential Technological Strength) is the basis of the ranking which provides an assessment of a company's innovation competitiveness. ETS evaluates a company's performances in a specific industry by Number of Patents, CII and EPI in a certain year. ETS is derived from two quality indicators (CII and EPI) and one quantity indicator (Number of Patents). It is believed that, compared to TS, ETS gives a more precise assessment of a company's innovative strength as it takes into account of several quality indicators. The ETS of $i$ company in $j$ industry, ETS $S_{i j}$, can be computed by its number of patents, EPI, and CII as follow,

$$
E T S_{i j}=P_{i j} \times E P I_{i j} \times C I I_{i j}
$$

\section{Results}

To display over all patenting status in Taiwan, a general search of patent performance was conducted. This analysis searched patents granted in USPTO database. Taiwan is chosen as the country of assignee, the year of issued date is set from 1998 to 2003, and the first seventy assignees were selected. Since the data in USPTO database is in English, names of Taiwan assignee do not have a uniform format. Besides, many companies had been merged or independent from a corporation. Therefore this study takes the authority control on the assignee name before any statistical analysis can proceed.

The patent search includes two-stages. The first stage focuses on the performance of the total number of patents of the targeted Taiwanese industries. The number of patents from the top seventy assignees in 2003 and their averages from 1998 to 2002 were collected and computed. This study includes utility and design patents in the first stage. Therefore, the search strategy here focuses on "all patents of the top seventy Taiwan patent assignees in the USA from 1998 to 2003".

Table 1 summarized the number of patents as an indication of R\&D output profile of Taiwanese companies and research institutes. As shown in Table 1, even though the patenting status of Hon Hai Precision falls behind Taiwan Semiconductor Manufacturing and United Microelectronic from 1998 to 2002, this company held 483 patents granted in the USA and ranked number one in 2003. Industrial Technology Research Institute, a non-profit organization, also maintains a stable performance throughout the years. Generally speaking, number of patents increased over the years for most of the companies. 
D.-Z. CHEN et al.: Essential Patent Index and Essential Technological Strength

Table 1. Number of Patents of Taiwan companyies/institutes

\begin{tabular}{|c|c|c|c|c|}
\hline \multirow{3}{*}{$\begin{array}{l}\text { Company / Institute } \\
\text { Hon Hai Precision Ind. Co. }\end{array}$} & \multicolumn{4}{|c|}{ Rank (No. of Patents) } \\
\hline & \multicolumn{2}{|c|}{2003} & \multicolumn{2}{|c|}{ 1998-2002 Avg } \\
\hline & 1 & $(483)$ & 3 & $(272.4)$ \\
\hline Taiwan Semiconductor Manufacturing Co. & 2 & $(434)$ & 1 & $(428.6)$ \\
\hline Industrial Technology Research Institute, Taiwan & 3 & $(207)$ & 4 & $(211.6)$ \\
\hline United Microelectronic Corp. & 4 & (188) & 2 & $(398.2)$ \\
\hline Macronix International Co. & 5 & $(182)$ & 9 & $(49.8)$ \\
\hline Delta Electronics Inc. & 6 & $(82)$ & 11 & $(24.6)$ \\
\hline HannStar Display Corp. & 7 & (79) & 48 & $(3.6)$ \\
\hline Winbond Electronics Corp. & 8 & (77) & 6 & $(103.8)$ \\
\hline Siliconware Precision Industries Co. & 9 & $(60)$ & 13 & $(18.8)$ \\
\hline BenQ Corp. & 10 & (58) & 12 & $(20.2)$ \\
\hline Via Technologies, Inc. & 11 & $(52)$ & 17 & $(16)$ \\
\hline Umax Data Systems Inc. & 12 & $(48)$ & 19 & (14.6) \\
\hline Silicon Integrated Systems Corp. & 13 & $(41)$ & 21 & $(12.6)$ \\
\hline AU Optronics Corporation & 14 & (40) & 54 & $(2.4)$ \\
\hline Mosel Vitelic, Incorporated & 15 & $(40)$ & 8 & $(63.2)$ \\
\hline Promos Technologies, Inc. & 16 & (36) & 18 & $(15.2)$ \\
\hline Sunonwealth Electric Machine Industry Co. & 17 & (36) & 24 & $(10)$ \\
\hline Silitek Corp. & 18 & $(31)$ & 25 & $(9.6)$ \\
\hline Hannspree, Inc. & 19 & $(31)$ & 67 & $(0)$ \\
\hline National Science Council & 20 & $(28)$ & 7 & $(71.4)$ \\
\hline TYC Brother Industrial Co. & 21 & (28) & 57 & $(1.8)$ \\
\hline Vanguard International Semiconductor Corp. & 22 & (27) & 5 & $(107.2)$ \\
\hline Inventec Corp. & 23 & $(26)$ & 14 & $(18.6)$ \\
\hline Nanya Technology Corp. & 24 & (25) & 22 & $(11.8)$ \\
\hline Shin Yeh Enterprise Co. & 25 & (24) & 55 & (2) \\
\hline Quanta Computer Inc. & 26 & (24) & 59 & $(1.6)$ \\
\hline Primax Electronics & 27 & (23) & 15 & $(17.6)$ \\
\hline Globe Union Industrial Corp. & 28 & (21) & 31 & $(5.8)$ \\
\hline Advanced Semiconductor Engineering, Inc. & 29 & (20) & 16 & $(17.4)$ \\
\hline Accton Technology Corp. & 30 & (19) & 42 & $(4.2)$ \\
\hline Chung Shan Institute of Science and Technology & 31 & (18) & 27 & (9) \\
\hline Mustek Systems, Inc. & 32 & $(18)$ & 10 & $(25.8)$ \\
\hline Basso Industry Corp. & 33 & $(17)$ & 50 & (3) \\
\hline Avision Inc. & 34 & (16) & 34 & (5) \\
\hline Behavior Tech Computer Corp. & 35 & (16) & 23 & $(10.4)$ \\
\hline
\end{tabular}

continued on the next page 
D.-Z. CHEN et al.: Essential Patent Index and Essential Technological Strength

Table 1. (cont.)

\begin{tabular}{|c|c|c|c|c|}
\hline \multirow{3}{*}{$\begin{array}{l}\text { Company / Institute } \\
\text { Darfon Electronics Co. }\end{array}$} & \multicolumn{4}{|c|}{ Rank (No. of Patents) } \\
\hline & \multicolumn{2}{|c|}{2003} & \multicolumn{2}{|c|}{ 1998-2002 Avg. } \\
\hline & 36 & $(16)$ & 21 & $(5.4)$ \\
\hline Academia Sinica & 37 & (14) & 28 & $(7.8)$ \\
\hline Compal Electronic, Inc. & 38 & (14) & 19 & $(14.6)$ \\
\hline Faraday Technology Corp. & 39 & $(14)$ & 45 & $(3.8)$ \\
\hline Nanya Plastics Corp. & 40 & (14) & 49 & $(3.4)$ \\
\hline Shin Jiuh Corp. & 41 & (14) & 29 & $(7.6)$ \\
\hline Far Great Plastics Industrial Co. & 42 & $(14)$ & 33 & $(5.2)$ \\
\hline eMemory Technology & 43 & $(13)$ & 59 & $(1.6)$ \\
\hline Acer Inc. & 44 & (13) & 38 & $(4.6)$ \\
\hline Chi Mei Optoelectronics Corp. & 45 & $(13)$ & 37 & $(4.8)$ \\
\hline Wistron Corp. & 46 & (13) & 67 & $(0)$ \\
\hline Taiwan Fu Hsing Industrial Co. & 47 & (13) & 39 & $(4.4)$ \\
\hline Grand HC Auto Tooling Corp. & 48 & $(12)$ & 67 & $(0)$ \\
\hline Powerchip Semiconductor Corp. & 49 & (11) & 29 & $(7.6)$ \\
\hline MiTac International Corp. & 50 & $(11)$ & 45 & $(3.8)$ \\
\hline Shin Tai Spurt Water of the Garden Tools Co. & 51 & $(11)$ & 39 & $(4.4)$ \\
\hline All-Line Inc. & 52 & $(11)$ & 26 & $(9.4)$ \\
\hline Chao Ling Chemical Industry Co. & 53 & $(11)$ & 65 & $(0.6)$ \\
\hline ASUSTek Computer Inc. & 54 & $(10)$ & 34 & $(5)$ \\
\hline Ritek Corp. & 55 & $(10)$ & 44 & (4) \\
\hline General Plastic Industrial Co. & 56 & (10) & 53 & $(2.6)$ \\
\hline Lite-On It Corp. & 57 & $(10)$ & 59 & $(1.6)$ \\
\hline Global Sun Technology Inc. & 58 & $(10)$ & 67 & $(0)$ \\
\hline Hiwin Technologies Corp. & 59 & (9) & 63 & $(1.4)$ \\
\hline Megic Corp. & 60 & (9) & 55 & $(2)$ \\
\hline Prokia Technology Co. & 61 & (9) & 59 & $(1.6)$ \\
\hline Nien Made Enterprise Co. & 62 & $(8)$ & 57 & $(1.8)$ \\
\hline Chunghwa Picture Tubes & 63 & (8) & 42 & $(4.2)$ \\
\hline Inventec Appliances Corp. & 64 & $(8)$ & 51 & $(2.8)$ \\
\hline Lundar Electric Industrial Co. & 65 & $(8)$ & 45 & $(3.8)$ \\
\hline Yen Sun Technology Corp. & 66 & (7) & 63 & $(1.4)$ \\
\hline Ritdisplay Corp. & 67 & (7) & 66 & $(0.4)$ \\
\hline Uni-Splendor Corp. & 68 & (7) & 51 & $(2.8)$ \\
\hline AIPTEK International Inc. & 69 & (7) & 39 & $(4.4)$ \\
\hline Auden Technology Corp. & 70 & (6) & 34 & $(5)$ \\
\hline
\end{tabular}

Data source: Original data from USPTO Patent Database and figures are calculated by the authors. 
To evaluate the competitiveness of enterprises, the second step was to remove four non-profit assignees, Industrial Technology Research Institute, Taiwan National Science Council, Chung Shan Institute of Science and Technology, and Academia Sinica from the result of the first-step search. The remaining 66 companies were then further grouped into three industry categories in order to make their performance comparable. Semiconductor, computer system, and computer peripheral and parts are chosen because of their international visibility and high-tech status. They are designated as the components of the high-tech industries by the CEPD (Council for Economic Planning and Development, Executive Yuan) of Taiwan. Since the number of utility patents granted is strongly associated with a company's R\&D and competition capabilities, only the number of utility patents of each company was collected from the database. In summary, the search strategy of the second stage focused on "the granted utility patents of every company in three industries in the USA from 1998 to 2003". The ETS for all the companies included in the study were calculated, followed by comparison of their TS and ETS. The weight factor of assignee company $\psi_{a, s}$ was set as 1 to simplify the correlations between companies at this stage.

\section{Semiconductor Industry}

16 companies were categorized as semiconductor industry. This research analyzed 15 of the 16 companies since one of them had no essential patent (Table 2).

Table 2. Semiconductor Industry: Patent indicators and rank

\begin{tabular}{lcccccccc}
\hline \multicolumn{1}{c}{ Company } & $\begin{array}{c}\text { ETS } \\
\text { Rank }\end{array}$ & ETS & $\begin{array}{c}\text { TS } \\
\text { Rank }\end{array}$ & TS & No. of Utility Patent* CII EPI** \\
& 1 & 672.70 & $1(0)$ & 542.50 & 434 & $(425)$ & 1.25 & 1.24 \\
Taiwan Semiconductor Manufacturing Co. & 1 & & & \\
Macronix International Co. & 2 & 167.57 & $2(0)$ & 180.18 & 182 & $(49.8)$ & 0.99 & 0.93 \\
United Microelectronic Corp. & 3 & 124.76 & $3(0)$ & 148.52 & 188 & $(395.8)$ & 0.79 & 0.84 \\
Siliconware Precision Industries Co. & 4 & 76.59 & $4(0)$ & 69.00 & 60 & $(18.8)$ & 1.15 & 1.11 \\
Vanguard International Semiconductor Corp. & 5 & 43.55 & $6(+1)$ & 34.29 & 27 & $(106.6)$ & 1.27 & 1.27 \\
Advanced Semiconductor Engineering, Inc. & 6 & 35.63 & $8(+2)$ & 26.20 & 20 & $(17)$ & 1.31 & 1.36 \\
Nanya Technology Corp. & 7 & 33.28 & $9(+2)$ & 26.00 & 26 & $(10)$ & 1.00 & 1.28 \\
Winbond Electronics Corp. & 8 & 33.03 & $5(-3)$ & 56.94 & 73 & $(103.2)$ & 0.78 & 0.58 \\
Silicon Integrated Systems Corp. & 9 & 32.34 & $7(-2)$ & 27.88 & 41 & $(12.4)$ & 0.68 & 1.16 \\
Powerchip Semiconductor Corp. & 10 & 30.07 & $11(+1)$ & 19.03 & 11 & $(7.6)$ & 1.73 & 1.58 \\
Via Technologies, Inc. & 11 & 14.14 & $13(+2)$ & 17.68 & 52 & $(16)$ & 0.34 & 0.80 \\
Mosel Vitelic, Inc. & 12 & 13.78 & $9(-3)$ & 26.00 & 40 & $(63.2)$ & 0.65 & 0.53 \\
Megic Corp. & 13 & 10.15 & $14(+1)$ & 8.46 & 9 & $(2)$ & 0.94 & 1.20 \\
Promos Technologies, Inc. & 14 & 7.86 & $12(-2)$ & 18.72 & 36 & $(15.2)$ & 0.52 & 0.42 \\
Faraday Technology Corp. & 15 & 2.35 & $15(0)$ & 5.60 & 14 & $(3.8)$ & 0.40 & 0.42 \\
\hline
\end{tabular}

* In bracket is the average number of patents from 1998 to 2002

** Calculated by patents from 1998 to 2002.

Data source: Original data from USPTO Patent Database \& figures are calculated by the authors. 
ETS value was used to rank these companies and the value/ranking of TS was shown as well. The differences of ETS and TS ranking were presented in the bracket after the TS rank. CII and EPI of each company were juxtaposed for emphasizing the differences.

The analysis of patent performance reveals that Taiwan Semiconductor Manufacturing has the highest ETS value (672.70), Macronix International comes in second with an ETS value of 167.57. The third place is United Microelectronics with an ETS value of 124.76. ETS values of top three companies were all greater than 120. As shown in Table 2, a great gap exists between the Big three and the rest as the ETS value of the $4^{\text {th }}$ company scores as low as 76.59 , and those from the $5^{\text {th }}$ to $10^{\text {th }}$ companies ranged from 30 to 40 . The third tier falls even further behind as none of the rest has a score higher than 20. Based on ETS values, three groups of companies with drastic difference on performance can be distinguished.

The reason behind Taiwan Semiconductor Manufacturing's on ETS is due to the fact that it had as many as 434 patents granted in 2003, compared to Macronix International's (182) and United Microelectronic's (188). On the other hand, Taiwan Semiconductor Manufacturing also had outstanding performance for EPI and CII, where it is ranked within top five in the semiconductor industry. The scores are consistent with the general perception of its industry leading status. In the TS and ETS ranking, there is no change of order for the top four and the bottom one but variations appeared in between. EPI values of Winbond Electronics and Mosel Vitelic were both much lower than the expected value 1, causing their ranking in ETS to drop as well. This means, the technological innovation competitiveness of these two companies were weaker than the overall technological force. By contrast, Advanced Semiconductor Engineering and Nan Ya Technology have much better EPI values and their ETS ranking were lifted, showing better competitiveness of innovation.

One particular case about the unique contribution of CII and EPI in technological output evaluation is the example of Powerchip Semiconductor. Powechip Semiconductor only held 11 patents in 2003, and was ranked 14 out of the 15 companies. However, its CII and EPI are both the highest in the semiconductor industry, making the TS ranking go up to $11^{\text {th }}$ and ETS ranking move up to number 10. It is clear that if number of patents were the only indicator for comparison, a company with outstanding competitiveness of innovation would have been overlooked.

\section{Computer System Industry}

In 2003, six companies are categorized into the computer system industry. Two of them were excluded from the list since they did not own any essential patent. This research analyzed the remaining four companies in this domain and the results were shown in Table 3. 
D.-Z. CHEN et al.: Essential Patent Index and Essential Technological Strength

Table 3. Computer System Industry: Patent indicators and rank

\begin{tabular}{lcccccccc}
\hline \multicolumn{1}{c}{ Company } & $\begin{array}{c}\text { ETS } \\
\text { Rank }\end{array}$ & ETS & $\begin{array}{c}\text { TS } \\
\text { Rank }\end{array}$ & TS & No. of Utility Patent* & CII & EPI** \\
\hline Acer Inc. & 1 & 35.01 & $1(0)$ & 18.33 & 13 & $(4.6)$ & 1.41 & 1.91 \\
Compal Electronic, Inc. & 2 & 5.96 & $3(+1)$ & 9.94 & 14 & $(14.6)$ & 0.71 & 0.60 \\
Inventec Corp. & 3 & 5.73 & $2(-1)$ & 15.08 & 26 & $(17)$ & 0.58 & 0.38 \\
MiTac International Corp. & 4 & 3.97 & $4(0)$ & 6.30 & 9 & $(3.8)$ & 0.70 & 0.63 \\
\hline
\end{tabular}

* In bracket is the average number of patents from 1998 to 2002

** Calculated by patents from 1998 to 2002.

Data source: Original data from USPTO Patent Database \& figures are calculated by the authors.

For the analysis on patent performance for computer system industry, Acer obtained the highest ETS value (35.01). As shown in Table 3, Acer is the only company that had an EPI value higher than the expected value 1. This higher EPI value also produced a better ETS value compared to other companies. By contrast, Inventec is another excellent example for the application of EPI. Even though Inventec held the most patents in the industry, its EPI turns out to be the lowest, which resulted in its low ETS ranking, too. All of these facts point to the fact that the patents issued by Inventec tend to be of lower quality. Clearly, using of EPI factor helps accent the difference.

Besides, Inventec and Compal Electronic had similar CII values. Invetec had better TS ranking since their number of patents is approximately two-fold of that of Compal Electronic. However, EPI value of Compal Electronic is much higher than Inventec's and this produced a better ETS value for Compal Electronic. This case shows that the weight of essential patent will reduce the influence of number of patents and emphasize the measuring of technological innovation competitiveness.

\section{Computer Peripheral and Parts Industry}

Twelve companies were categorized into the computer peripheral and parts industry. One of them was excluded from the list since it did not own any essential patent in 2003. The results of the remaining 11 companies in this domain were shown in Table 4.

Hon Hai Precision had the best ETS performance, as shown in Table 4. Both its number of utility patents and EPI value were the highest in the industry. When comparing to the second company on the list, Delta Electronics, Hon Hai Precision had a TS value six times higher and an ETS value eleven times higher, which explain Hon Hai's industry leading status. This result demonstrated the fact that ETS put more accents on the innovation force than TS alone. 
D.-Z. CHEN et al.: Essential Patent Index and Essential Technological Strength

Table 4. Computer Peripheral and Parts Industry: Patent indicators and rank

\begin{tabular}{lcccccccc}
\hline \multicolumn{1}{c}{ Company } & $\begin{array}{c}\text { ETS } \\
\text { Rank }\end{array}$ & ETS & TS Rank & TS & No. of Utility Patent** & CII & EPI** \\
\hline Hon Hai Precision Ind. Co. & 1 & 561.44 & $1(0)$ & 460.20 & 390 & $(269.6)$ & 1.18 & 1.22 \\
Delta Electronics Inc. & 2 & 50.41 & $2(0)$ & 75.24 & 76 & $(24.6)$ & 0.99 & 0.67 \\
Shin Jiuh Corp. & 3 & 17.95 & $5(+2)$ & 15.47 & 13 & $(7.6)$ & 1.19 & 1.16 \\
BenQ Corp. & 4 & 17.10 & $3(-1)$ & 28.98 & 42 & $(29.6)$ & 0.69 & 0.59 \\
Silitek Corp. & 5 & 11.89 & $4(-1)$ & 20.50 & 25 & $(9.6)$ & 0.82 & 0.58 \\
Ritek Corp. & 6 & 8.28 & $9(+3)$ & 6.90 & 10 & $(4)$ & 0.69 & 1.20 \\
Behavior Tech Computer Corp. & 7 & 5.45 & $7(0)$ & 9.90 & 15 & $(10.2)$ & 0.66 & 0.55 \\
Mustek Systems, Inc. & 8 & 2.97 & $10(+2)$ & 5.94 & 18 & $(25.6)$ & 0.33 & 0.50 \\
ASUSTek Computer Inc. & 9 & 2.94 & $11(+2)$ & 4.60 & 10 & $(5)$ & 0.46 & 0.64 \\
Avision Inc. & 10 & 1.41 & $8(-2)$ & 8.80 & 16 & $(5)$ & 0.55 & 0.16 \\
Umax Data Systems Inc. & 11 & 1.16 & $6(-5)$ & 10.56 & 48 & $(14.4)$ & 0.22 & 0.11 \\
\hline
\end{tabular}

* In bracket is the average number of patents from 1998 to 2002.

** Calculated by patents from 1998 to 2002.

Data source: Original data from USPTO Patent Database \& figures are calculated by the authors.

Ritek and ASUSTek had similar number of patents and CII value. However, Ritek ranked $6^{\text {th }}$ in the EPI ranking and ASUSTek fell far behind. The difference was mainly caused by the EPI values. Ritek's EPI value is 1.2 but ASUSTek scored only 0.64 . Apparently, without using EPI, the innovation competitiveness of ASUSTek would have been over estimated.

As for the rest of the list, Ritek and Avision had similar number of patents and CII values and Ritek ranked lower than Avision in TS ranking. However, Ritek had a much higher EPI value (1.2), compared to what Avision had (0.16), resulting in a significant difference on ETS values. Another similar comparison is between Ritek and Umax Data Systems. Even though Umax Data Systems has five times the number of patents than Ritek does, the significant difference on EPI values produced great difference on their ETS values, making Umax Data Systems the worst one on the list.

\section{Discussion}

In high-tech industry, the innovation capacity is arguably the most important competitive edge a company can enjoy. It plays a major role not only in competitivecooperative relationship of companies but also in the strategic patent portfolios. The number of patents owned by a company is often used as the formal measure of a company's innovation capacity. Yet as pointed out earlier, patent counts along gives a rather imprecise, sometimes misleading picture. 
In this study, time-factor was added to form two new indicators, EPI and ETS. The ETS considers the number of patents, citations and essential patents all at the same time, with an aim to capture a company's innovation capacity.

This research studies three high-tech industries in Taiwan in order to test the validity of EPI and ETS values. As shown in Tables 2, 3 and 4, we have identified several cases where companies had better ETS ranking than their TS ranking due to their higher EPI performance. Without the identification of essential patents and treating all citation patents as the same tend to lose sight of the true value of citations. Giving different weight to essential patents highlights the importance of citation impact on the assessment of a company's innovation capacity.

We have shown that ETS is better quipped to differentiate the subtle differences in the innovative capacity of companies. For example, the patent numbers of Powerchip Semiconductor and Ritek are both low in their respective industries, even though the CII value of Ritek sits on the middle level. If TS indicator had been used solely, the great innovation competitiveness of Powechip and Ritek would not have been recognized. Furthermore, there are cases where firms' innovative capacity can only be differentiated by their EPI AND ETS as several companies share similar number of patents and CII values, this happens between Siliconware Precision Industries and Winbond Electronics in semiconductor; and between Behavior Tech Computer, Avision, Ritek and ASUSTek in computer peripheral and parts industry.

This research does not find any conclusive relationships between number of granted patents and patent quality. There are many cases where a positive relationship between the two can be found. Yet Powechip Semiconductor in semiconductor industry and Riteck Corp. in Computer Peripheral and Parts Industry are two exceptions to the rule. These two companies owned small number of patens but those patens have outstanding EPI values, providing these companies better ETS rankings. Further research need to be done to understand the relationships between quantity and quality oriented measures.

Weighting factors such as citation lag time factor and citation assignee were incorporated in this study. Our findings seem to point to the higher discriminate value of EPI and ETS. To take more steps ahead, other characters of citation, such as citing and cited pattern, legal status, and technology classification factors, should be taken into consideration in further researches.

\section{References}

Acosta, M., Coronado, D. (2003), Science-technology flows in spanish regions: An analysis of scientific citations in patents. Research Policy, 32 : 1783-1803.

Albert, M. B., Avery, D., NArin, F., McAllister, P. (1991), Direct validation of citation counts as indicators of industrially important patents. Research Policy, $20: 251-259$. 
D.-Z. CHEN et al.: Essential Patent Index and Essential Technological Strength

Albert, M. B., Yoshida, P. G., Opstal, D. (1998), The New Innovators: Global patenting trends in five sectors. U.S. Department of Commerce, Office of Technology Policy. Retrieved October 12, 2004 from: http://www.technology.gov/Reports/09111998.pdf

BreitzMAn, A. F., NARIN, F. (2001), Method and apparatus for choosing a stock portfolio, based on patent indicators, United States Patent, 6175824.

Chen, D.-Z, HuAng, M.-H., LIN, W.-Y. C. (2003), The Industrial technological Innovation Scoreboard: Evaluating by number of patents and citation. Taiwan Economic Research Monthly, 26 : 87-93. (in Chinese)

Dunlop, L., OpPEINHEIM, C. (1980), The effect of recycling on a patent citation network. World Patent Information, 2 (3) : 100-102.

Ellis, P., Hepburn, G., OpPenheim, C. (1978), Studies on patent citation networks. Journal of Documentation, 34 (1) : 12-20.

GARG, K. C., PADHI, P. (1998), Scientometric study of laser patent literature. Scientometrics, 43 : $443-454$.

Hagedoorn, J., Cloodt, M. (2003), Measuring innovative performance: Is there an advantage in using multiple indicators? Research Policy, 32 : 1365-1379.

Hall, B. H., JAFFe, A., Trajtenberg, M. (2000), Market value and patent citations: A first look. NBER Working Paper, No. w7741.

HIRSCHEY, M., RICHARDSON, V. J. (2004), Are scientific indicators of patent quality useful to investors? Journal of Empirical Finance, 11 (1) : 91-107.

Hu, A. G. Z., JAFFE, A. B. (2003), Patent citations and international knowledge flow: The cases of Korea and Taiwan. International Journal of Industrial Organization, 21 (6) : 849-880.

KARKI, M. M. S. (1997), Patent citation analysis: A policy analysis tool. World Patent Information, 19 (4) : 269-272.

KoEnIG, M. E. D. (1983), A bibliometric analysis of pharmaceutical research. Research Policy, 12 (1) : $15-36$.

MEYER, M. (2002), Tracing knowledge flows in innovation systems. Scientometrics, 54 (2) : 193-212.

NARIN, F., OLIVASTRO, D. (1998), Linkage between patents and papers: An interim EPO/US comparison. Scientometrics, $41: 51-59$.

Narin, F., Albert, M., Kroll, P., Hicks, D. (2000), Inventing Our Future: The Link Between Australian Patenting and Basic Science. Commonwealth of Australia. Retrieved October 12, 2004 from: http://www.arc.gov.au/pdf/00_02.pdf

NArin, F., Noma, E., PERry, R. (1987), Patents as indicators of corporate technological strength. Research Policy, 16 (2-4) : 143-155.

NunN, H., OPPENHEIM, C. (1980), A patent-journal citation network on prostaglandins. World Patent Information, 2 (2) : 57-60.

RozhKov, S., Ivantcheva, L. (1998), Scientometrical indicators of national science \& technology policy based on patent statistics data. World Patent Information, 20 (3-4) : 161-166.

Technology ReVIEW \& CHI RESEARCH (2004), 2004 Technology Review Patent Scorecard. Retrieved January 15, 2005 from: http://www.technologyreview.com/articles/downloads/patents0504.xls

TripPe, A. J. (2003), Patinformatics: Tasks to tools. World Patent Information, 25 (3) : 211-221.

WORLD ECONOMIC FORUM (2004), Global Competitiveness Report 2004-2005: Executive summary. Retrieved Jan. 10, 2005 from: http://www.weforum.org/pdf/Gcr/Executive Summary GCR 04

World BANK (2005a), Knowledge Assessment Methodology (KAM) Home Page. Retrieved Aug. 26, 2005 from: http://info.worldbank.org/etools/kam2005/

WORLD BANK (2005b), Basic Scorecard. Retrieved Aug. 26, 2005 from: http://info.worldbank.org/etools/kam2005/html/basic_scorecard.htm

Wu, R.-I. (2000), The Measurement and International Competitiveness of a New Taiwan Economic Indicator. Retrieved December 10, 2004 from: http://www.tier.org.tw/07publication/president/28.htm (in Chinese) 